\title{
Pilot study of blood perfusion coherence along the meridian in forearm
}

\author{
Guangjun Wang, Yuying Tian, Shuyong Jia, Wenting Zhou and Weibo Zhang*
}

\begin{abstract}
Background: Many studies have explored the relationship between skin microcirculation and meridian activation. However, few studies have examined blood perfusion coherence along the meridians, and other studies have suggested that the skin vasodilator response relates to age. This study investigated blood perfusion coherence characteristics along the meridian of the forearm in healthy volunteers.
\end{abstract}

Methods: A total of 15 young subjects $(25.53 \pm 2.20)$ and 15 middle-aged subjects $(50.07 \pm 3.37)$ were recruited for this study. Before experiments, each subject was placed in a temperature-controlled room for $60 \mathrm{~min}$. Skin blood perfusion from five points was recorded simultaneously using a full-field laser perfusion imager before and after inflatable occlusion. The five points comprised three points located on the pericardium meridian, and two points from different locations. Coherence analysis between these points was performed at different frequency intervals from 0.0095 to $2 \mathrm{~Hz}$.

Results: In young subjects, the coherence value was unchanged before and after occlusion, and there was no significant difference in coherence value between meridian-meridian points (M-M) and meridian-parameridian points (M-P). In middle-aged subjects, the coherence value increased significantly in both $\mathrm{M}-\mathrm{M}$ and $\mathrm{M}-\mathrm{P}$ at frequency intervals of $0.14-0.4 \mathrm{~Hz}, 0.4-1.6 \mathrm{~Hz}$, and 1.6-2 Hz. However, there was no significant difference in coherence values between M-M and M-P.

Conclusions: Inflatable occlusion can increase middle-aged subjects' blood perfusion coherence value of the forearm. However, there is no specificity in meridian location.

Keywords: Coherence analysis, Full-field laser blood perfusion imaging, Meridian, Age, Inflatable occlusion

\section{Background}

In Traditional Chinese Medical (TCM) theory, the acupuncture effect is based on the integrity function of the meridian, which in turn is the core concept of metaphysical acupuncture theory [1]. However, it is difficult to evaluate the activation of meridians. Until now, the broad consensus in meridian studies has been the lower impedance along the meridians [2,3]. Usually, the impedance of the skin is proportional to the interstitial fluid volume arising from microcirculation; thus, microcirculation may be an index for meridian activation. In addition, some studies have suggested that the meridian system may contain a continuous channel [4] to facilitate signal transport in peripheral tissues [5,6], which provides further evidence for the relationship between microcirculation and meridians [7]. Although much attention has

\footnotetext{
* Correspondence: zhangweibo@hotmail.com

Institute of Acupuncture and Moxibustion, China Academy of Chinese Medical Sciences, Beijing, China
}

been focused on improving the understanding of the relationship between meridians and microcirculation [8-10], the synchronous characteristics of blood perfusion along meridians are still unknown. Thus, the purpose of the current study was to quantify the frequency-dependent covariation of blood perfusion along meridians using the cross-spectral analyses (coherence) method.

Previous studies had indicated that blood-flow oscillations at frequencies from 0.009 to $1.6 \mathrm{~Hz}$ might reflect various physiological rhythms [11], which can be separated into five different frequency bands in frequency domain [12-15]. Thus the blood perfusion signal contains a mixture of the influence of endothelial activity, neurogenic activity, intrinsic myogenic activity, respiration, and heart rate. Different frequency bands show different clinical implications. On the other hand, coherence is a measure of the correlation of two signals. If the investigated two signals are assumed to be stationary, then the coherence can be calculated to estimate 
the correlation of the signals at different frequencies. Coherence analysis has been used widely in biosignal analysis, not only in EEG and EMG [16], but also in the blood flow analysis [17]. So coherence is a suitable method for blood perfusion analysis.

\section{Methods}

\section{Ethics statement}

This study was reviewed and approved by the Institutional Review Board at the Institute of Acupuncture \& Moxibustion, China Academy of Chinese Medical Sciences (CACMS). Each subject provided informed consent and had an adequate understanding of the procedure and purpose of this study.

\section{Subjects}

Fifteen healthy young subjects(Group I,n = 15) aged from 21 to $30(25.53 \pm 2.20)$ and fifteen healthy middle age subjects(Group II,n=15) aged from 46 to $57(50.07 \pm$ 3.37) were recruited for this study. All younger subjects were students from the CACMS and Beijing University of Chinese Medicine. All middle-aged subjects were from the CACMS. All subjects had no past history of disease, and had not taken any medication in the past 6 months (Table 1).

\section{Protocol for measurement of mean blood flux}

Upon arrival at the laboratory, subjects were placed in a temperature-controlled room $\left(24-26^{\circ} \mathrm{C}\right)$ for $60 \mathrm{~min}$. Measurements of skin blood perfusion were carried out using full-field laser blood perfusion imaging (FLPI, Moor Instruments, Devon, UK). Before recording, the left arm was immobilized to ensure positioning and during the recording, the subject remains supine position. The single point (32-36 pixels) measurements model was selected.

In the TCM theory, both acupoint and meridian are core concept to explain the acupuncture effect. According to the meridian theory, the acupuncture information might be transported along the meridian continuously. So the meridian channel has its' own specificity compared with the parameridian area. Our aim is to investigate the meridian specificity with blood perfusion coherence analysis, but not the acupoint specificity. In this study, a total of 5 points (described as channels in the Moor FLPI recording software) were used for recordings (Figure 1A). Point 1 (Channel 1, Ch1) was the midpoint of Quze (PC3) and Daling (PC7), all of which belong to the pericardium meridian. Point 4 (Channel 4, Ch4) was located on the radial side of the pericardium meridian, while Point 5 (Channel 5, Ch5) was located on the ulnar side. Point 2 (Channel 2, Ch2) and Point 3 (Channel 3, Ch3) were both located on the pericardium meridian, Ch3 on the proximal side and Ch2 on the distal side. Ch1 and the other four channels were equidistant.

For every acupunctist, the $\mathrm{PC}$ meridian in forearm is defined by the $\mathrm{PC} 7$ and $\mathrm{PC} 3$, thus the recording point 1 , 2 and 3 belong to the PC meridian. Recording point 4 and 5 obviously don't belong to the PC meridian. On the other hand, how far the distance between the recording points will be another considering factor. In this study, the diameter was quartered by the point 4 , point 1 and point 5. Thus the distance from point 1 to other four points is equal, and the bias due to the different distance between recording points will be ruled out.

$25-\mathrm{Hz}$ sample rate, an 8.33-ms exposure time, and $0.5 \mathrm{~s}$ time constant were set. After skin blood perfusion had been recorded for $30 \mathrm{~min}$, skin ischemia was induced by inflating a pneumatic cuff just above the elbow, with pressure maintained at $30 \mathrm{mmHg}$ for $3 \mathrm{~min}$. After this time, the pneumatic cuff was instantaneously deflated, and skin blood perfusion was recorded for another $30 \mathrm{~min}$. During the experiment, the laboratory room was kept in dark lighting conditions, and the protocol for measurement operation was strictly adhered to. The measurement process is illustrated in Figure 1A, and the original signal shown in Figure 1B.

\section{Data analysis}

To calculate the coherence between $\mathrm{Ch} 1$ and the other four channels, the coherence value was estimated as follows $[18,19]$ :

Table 1 Main characteristics of the studied individuals

\begin{tabular}{|c|c|c|c|c|}
\hline Characteristics & Group I & Group II & t-value & P-value \\
\hline Gender (Femal/man) & $10 / 5$ & $12 / 3$ & & \\
\hline Age (Years) & $25.53 \pm 2.20(21-30)$ & $50.07 \pm 3.37(46-57)$ & -23.614 & 0 \\
\hline Systolic pressure (mmHg) & $103.27 \pm 17.77(70-140)$ & $114.67 \pm 13.02(90-140)$ & -2.004 & 0.055 \\
\hline Diastolic pressure $(\mathrm{mmHg})$ & $71.13 \pm 10.04(60-90)$ & $80.00 \pm 11.18(60-90)$ & -2.286 & 0.030 \\
\hline Heart rate (BPM) & $69.134 \pm 9.924(52-86)$ & $66.33 \pm 5.99(56-76)$ & 0.936 & 0.358 \\
\hline High $(\mathrm{cm})$ & $163.07 \pm 4.067(157-172)$ & $162.87 \pm 5.11(153-173)$ & 0.119 & 0.906 \\
\hline Body weight (kg) & $56.47 \pm 5.597(47-70)$ & $61.60 \pm 8.07(50-77)$ & -2.025 & 0.520 \\
\hline Body mass index (BMI) & $21.21 \pm 1.68(18.36-24.34)$ & $23.16 \pm 2.24(20.20-27.34)$ & -2.694 & 0.012 \\
\hline
\end{tabular}




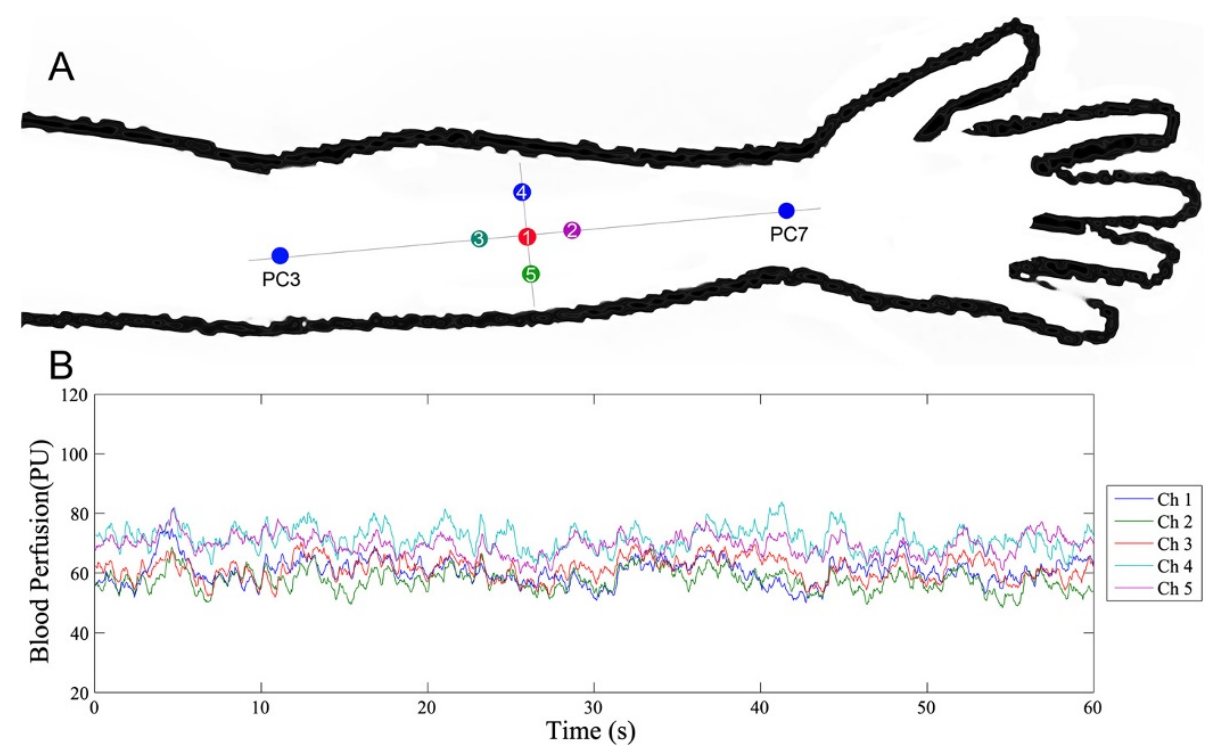

Figure 1 Illustration of the study design. (A) the measure points selection; (B) the original blood perfusion signal. PC, Pericardium Meridian; PC3, Quze acupoint; PC7, Daling acupoint. 1, 2, 3, 4, 5 represent the measurement points of Ch 1, Ch 2, Ch 3, Ch 4, Ch 5, respectively.

$$
C_{x y}(\mathrm{f})=\frac{\left|P_{x y}(\mathrm{f})\right|^{2}}{P_{x x}(\mathrm{f}) \mathrm{P}_{y y}(\mathrm{f})}
$$

This equation obtains the magnitude squared coherence estimate $C_{x y}(\mathrm{f})$ of the input signals $x$ and $y$ using Welch's averaged, modified periodogram method. The value of $C_{x y}(\mathrm{f})$ is between 0 and 1 and indicates how well $x$ corresponds to $y$ at each frequency. Computations were performed using the toolbox as follows in the MATLAB software (R2011a).

$$
\left[C_{x y}, F\right]=\text { mscohere }(x, y, \text { window, noverlap, } n f f t, f s)
$$

In this study, $x$ represents the Ch1 measurement value of blood perfusion, and $y_{\mathrm{i}}(\mathrm{i}=2,3,4,5)$ represents the signal of Ch2, Ch3, Ch4, and Ch5, respectively. window = hanning(1024), noverlap $=512$, $\mathrm{nfft}=20000$, and $\mathrm{fs}=25$. $C_{x y}$ is the coherence value at $F$ frequency. Then $F$ was segmented and 5 frequency bands $(0.0095-0.02 \mathrm{~Hz}, 0.02$ $0.06 \mathrm{~Hz}, 0.06-0.15 \mathrm{~Hz}, 0.15-0.4 \mathrm{~Hz}, 0.4-1.6 \mathrm{~Hz})$ were extracted according to the reference [20]. The mean $C_{x y}$ for every frequency band was calculated.

\section{Statistical analysis}

Group differences were analyzed using SPSS software (Version 13.0, SPSS Inc., Chicago, IL). The coherence values of blood perfusion in every frequency interval were expressed as mean \pm SD. Statistical analysis was performed using paired $t$-tests. Values of $\mathrm{p}<0.05$ were considered statistically significant.

\section{Results}

In this study, a total of 30 subjects were included in the final analyses. Figure 2 shows that irrespective of the coherence value associated with the measurement point, or the age group, the lower the frequency the higher the coherence value obtained. Additionally, we found that with an increase in frequency, the coherence value decreased.

In young subjects (Group I), the coherence value between Channel 1 and the other four channels was unchanged in each frequency interval before and after skin ischemia (Figure 2A, Table 2). However, in middle-aged subjects (Group II), the coherence value between Channel 1 and the other four channels increased significantly after skin ischemia in frequency intervals 3,4 , and 5 (Figure 2B, Table 3).

\section{Discussion}

Recently, increasing attention has been focused on the relationship between acupuncture and circulation [21-23]. Previous studies have indicated that acupuncture can not only affect the general circulation [24,25], but also affect skin microcirculation [20,22,26,27]. In addition, under resting conditions the mean blood perfusion was higher at the acupoints compared with surrounding tissues [10]. Moreover, adequate acupoint stimulation resulted in increased blood perfusion at this point, whereas blood perfusion of the non-acupoint only changed slightly after the same acupuncture stimulation $[28,29]$. Importantly, studies have suggested that the skin microvasculature mirrors the vascular function of other parts of the body [30-32], which is in line with the basic standpoints of acupuncture theory. 


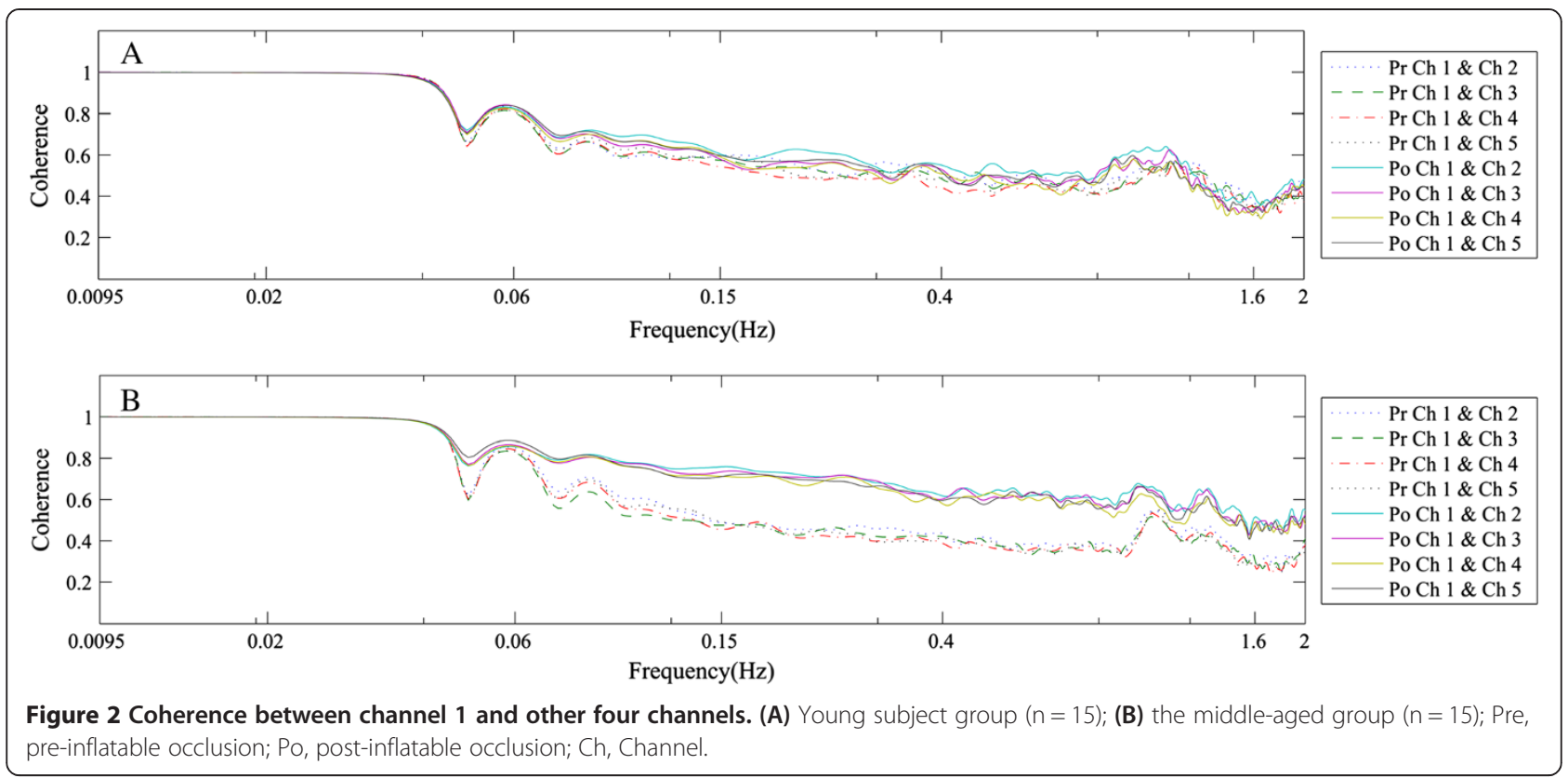

Many studies have indicated that ageing is associated with attenuated vasodilator responses of skin microcirculation as a result of a variety of stimuli [33-35]. In this study, we observed that occlusion resulted in different coherence values in middle-aged subjects. However, the coherence value changes were in frequency intervals 3,4 , and 5, which is not consistent with age-associated endothelial dysfunction [36]. In this regard, we believe that there are two possibilities. One is that the same stimuli for different age groups resulted in the different results. For young person, the stimuli of $30 \mathrm{mmHg}$ inflating occlusion last 3 min couldn't disturbance the normal function, while

Table 2 Coherence values of different frequency intervals before and after inflatable occlusion in Group I ( $n=15$ )

\begin{tabular}{|c|c|c|c|}
\hline Frequency intervals(Hz) & Channels & Pre & Post \\
\hline \multirow[t]{4}{*}{ FR1 $(0.0095-0.02)$} & Channel 1 to 2 & $0.9987 \pm 0.0009$ & $0.9983 \pm 0.0014$ \\
\hline & Channel 1 to 3 & $0.9987 \pm 0.0010$ & $0.9986 \pm 0.0010$ \\
\hline & Channel 1 to 4 & $0.9982 \pm 0.0022$ & $0.9982 \pm 0.0014$ \\
\hline & Channel 1 to 5 & $0.9985 \pm 0.0016$ & $0.9984 \pm 0.0016$ \\
\hline \multirow[t]{4}{*}{ FR2 (0.02-0.06) } & Channel 1 to 2 & $0.9059 \pm 0.0394$ & $0.9093 \pm 0.0656$ \\
\hline & Channel 1 to 3 & $0.8992 \pm 0.0439$ & $0.9117 \pm 0.0484$ \\
\hline & Channel 1 to 4 & $0.9003 \pm 0.0431$ & $0.9051 \pm 0.0482$ \\
\hline & Channel 1 to 5 & $0.9003 \pm 0.0400$ & $0.9074 \pm 0.0508$ \\
\hline \multirow[t]{4}{*}{ FR3 $(0.06-0.15)$} & Channel 1 to 2 & $0.6238 \pm 0.1984$ & $0.6876 \pm 0.2108$ \\
\hline & Channel 1 to 3 & $0.6198 \pm 0.1849$ & $0.6611 \pm 0.1994$ \\
\hline & Channel 1 to 4 & $0.6165 \pm 0.1959$ & $0.6671 \pm 0.1924$ \\
\hline & Channel 1 to 5 & $0.6364 \pm 0.1789$ & $0.6724 \pm 0.1959$ \\
\hline \multirow[t]{4}{*}{ FR4 (0.15-0.4) } & Channel 1 to 2 & $0.5478 \pm 0.2663$ & $0.5747 \pm 0.2851$ \\
\hline & Channel 1 to 3 & $0.5229 \pm 0.2664$ & $0.5375 \pm 0.2845$ \\
\hline & Channel 1 to 4 & $0.4903 \pm 0.2695$ & $0.5292 \pm 0.2956$ \\
\hline & Channel 1 to 5 & $0.5158 \pm 0.2674$ & $0.5527 \pm 0.2562$ \\
\hline \multirow[t]{4}{*}{ FR5 (0.4-1.6) } & Channel 1 to 2 & $0.4874 \pm 0.2334$ & $0.5111 \pm 0.2604$ \\
\hline & Channel 1 to 3 & $0.4680 \pm 0.2409$ & $0.4749 \pm 0.2545$ \\
\hline & Channel 1 to 4 & $0.4475 \pm 0.2358$ & $0.4519 \pm 0.2433$ \\
\hline & Channel 1 to 5 & $0.4586 \pm 0.2294$ & $0.4661 \pm 0.2398$ \\
\hline
\end{tabular}


Table 3 Coherence values of different frequency intervals before and after inflatable occlusion in Group II $(n=15)$

\begin{tabular}{|c|c|c|c|}
\hline Frequency intervals $(\mathrm{Hz})$ & Channels & Pre & Post \\
\hline \multirow[t]{4}{*}{ FR1 (0.0095-0.02) } & Channel 1 to 2 & $0.9988 \pm 0.0006$ & $0.9983 \pm 0.0019$ \\
\hline & Channel 1 to 3 & $0.9987 \pm 0.0009$ & $0.9984 \pm 0.0015$ \\
\hline & Channel 1 to 4 & $0.9987 \pm 0.0006$ & $0.9979 \pm 0.0031$ \\
\hline & Channel 1 to 5 & $0.9987 \pm 0.0009$ & $0.9984 \pm 0.0011$ \\
\hline \multirow[t]{4}{*}{ FR2 (0.02-0.06) } & Channel 1 to 2 & $0.9069 \pm 0.0434$ & $0.9221 \pm 0.0577$ \\
\hline & Channel 1 to 3 & $0.9044 \pm 0.0431$ & $0.9287 \pm 0.0452$ \\
\hline & Channel 1 to 4 & $0.9011 \pm 0.0587$ & $0.9247 \pm 0.0486$ \\
\hline & Channel 1 to 5 & $0.9047 \pm 0.0417$ & $0.9365 \pm 0.0365^{*}$ \\
\hline \multirow[t]{4}{*}{ FR3 $(0.06-0.15)$} & Channel 1 to 2 & $0.6034 \pm 0.2444$ & $0.7913 \pm 0.1889^{*}$ \\
\hline & Channel 1 to 3 & $0.5528 \pm 0.2543$ & $0.7806 \pm 0.1855^{*}$ \\
\hline & Channel 1 to 4 & $0.5673 \pm 0.2608$ & $0.7650 \pm 0.1974^{*}$ \\
\hline & Channel 1 to 5 & $0.5940 \pm 0.2276$ & $0.7671 \pm 0.1852^{*}$ \\
\hline \multirow[t]{4}{*}{ FR4 (0.15-0.4) } & Channel 1 to 2 & $0.4393 \pm 0.2808$ & $0.7206 \pm 0.2266^{* *}$ \\
\hline & Channel 1 to 3 & $0.4225 \pm 0.2846$ & $0.7103 \pm 0.2323^{* *}$ \\
\hline & Channel 1 to 4 & $0.4103 \pm 0.2826$ & $0.6950 \pm 0.2302^{* *}$ \\
\hline & Channel 1 to 5 & $0.4035 \pm 0.2904$ & $0.6930 \pm 0.2335^{* *}$ \\
\hline \multirow[t]{4}{*}{ FR5 (0.4-1.6) } & Channel 1 to 2 & $0.3939 \pm 0.2864$ & $0.6265 \pm 0.2242^{*}$ \\
\hline & Channel 1 to 3 & $0.3722 \pm 0.2754$ & $0.6070 \pm 0.2320^{*}$ \\
\hline & Channel 1 to 4 & $0.3739 \pm 0.2800$ & $0.5782 \pm 0.2147^{*}$ \\
\hline & Channel 1 to 5 & $0.3638 \pm 0.2829$ & $0.5889 \pm 0.2281^{*}$ \\
\hline
\end{tabular}

for middle-aged subjects, the same stimuli might be a up threshold stimuli and the body must be adaptive to the stress. The other is that both endothelial and neurogenic activity might only response to the specific stimuli, and the changes of intrinsic myogenic activity, respiration, and heart rate resulted from nonspecific stress.

In this study, Channels 1,2 , and 3 were located in the pericardial meridian, while Channels 4 and 5 were located in the parameridian position. According to acupuncture theory, the blood perfusion of Channels 1, 2, and 3 are all closely related, which could be the reason for the higher coherence values of these channels, whereas the coherence values between Channels 1 and 4, and Channels 1 and 5 should be lower. However, our results do not support this conjecture. We believe that one possible reason for this is that differences between the meridian and the parameridian positions do not exist. The other possible reason is that the stimulus in this study is lack of specificity. In the future, we should apply the specific stimuli at the different acupoint and then explore the coherence difference between M-M and M-P.

\section{Conclusions}

Skin ischemia can increase blood perfusion coherence values in the forearms of middle-aged subjects; however, there is no specificity in meridian location.
Competing interests

The authors declare that they have no competing interests.

\section{Author's contributions}

WG carried out the design and participated in data collection. TY, JS, and ZW participated in data collection. ZW led the design and participated in data collection. All authors read and approved the final manuscript.

\section{Acknowledgements}

This research was supported by the National Natural Science Foundation of China (81001553) and the Fundamental Research Funds for the Central Public Welfare Research Institutes (ZZO70806).

Received: 7 May 2013 Accepted: 19 November 2013 Published: 23 November 2013

\section{References}

1. Wang GJ, Ayati MH, Zhang WB: Meridian studies in China: a systematic review. J Acupunct Meridian Stud 2010, 3(1):1-9.

2. Rezaei S, Khorsand A, Jamali J: Characterisation of human skin impedance at acupuncture point PC4 Ximen and pericardium meridian using the four-electrode method. Acupunct Med 2012, 30(2):127-131.

3. Ahn AC, Park M, Shaw JR, McManus CA, Kaptchuk TJ, Langevin HM: Electrical impedance of acupuncture meridians: the relevance of subcutaneous collagenous bands. Plos One 2010, 5(7):e11907.

4. Li HY, Yang JF, Chen M, Xu L, Wang WC, Wang F, Tong JB, Wang CY: Visualized regional hypodermic migration channels of interstitial fluid in human beings: are these ancient meridians? J Altern Complement Med 2008, 14(6):621-628.

5. Zhang WB, Tian YY, Li H, Tian JH, Luo MF, Xu FL, Wang GJ, Huang T, Xu YH, Wang $\mathrm{RH}$ : A discovery of low hydraulic resistance channel along meridians. J Acupunct Meridian Stud 2008, 1(1):20-28. 
6. Li HY, Chen M, Yang JF, Yang CQ, Xu L, Wang F, Tong JB, LV Y, Suonan C: Fluid Flow along Venous Adventitia in Rabbits: Is It a Potential Drainage System Complementary to Vascular Circulations? Plos One 2012, 7:7.

7. Yao W, Li Y, Ding G: Interstitial fluid flow: the mechanical environment of cells and foundation of meridians. Evidence-based complementary and alternative medicine : eCAM 2012, 2012:853516.

8. Xu JS, Pan XH, Hu XL, Wu BH: Comparison between governor meridian and its bilateral control points in microcirculatory blood perfusion in 53 volunteer subjects. Zhen Ci Yan Jiu 2008, 33(5):321-325.

9. Ma SX, Li XY, Sakurai T, Pandjaitan M: Evidence of enhanced non-enzymatic generation of nitric oxide on the skin surface of acupuncture points: An innovative approach in humans. Nitric Oxide-Biol Ch 2007, 17(2):60-68

10. Hsiu H, Huang SM, Chao PT, Jan MY, Hsu TL, Wang WK, Wang YYL: Microcirculatory characteristics of acupuncture points obtained by laser Doppler flowmetry. Physiol Meas 2007, 28(10):N77-N86.

11. Bernardi L, Rossi M, Fratino P, Finardi G, Mevio E, Orlandi C: Relationship between phasic changes in human skin blood flow and autonomic tone. Microvasc Res 1989, 37(1):16-27.

12. Hsiu H, Hsu WC, Hsu CL, Huang SM: Assessing the effects of acupuncture by comparing needling the hegu acupoint and needling nearby nonacupoints by spectral analysis of microcirculatory laser Doppler signals. Evid-Based Compl Alt 2011, 2011:435928.

13. Thorn CE, Matcher SJ, Meglinski IV, Shore AC: Is mean blood saturation a useful marker of tissue oxygenation? Am J Physiol-Heart Circul Physiol 2009, 296(5):H1289-H1295.

14. Bernjak A, Clarkson PB, McClintock PV, Stefanovska A: Low-frequency blood flow oscillations in congestive heart failure and after beta1-blockade treatment. Microvasc Res 2008, 76(3):224-232.

15. Kvandal P, Landsverk SA, Bernjak A, Stefanovska A, Kvernmo HD, Kirkeboen KA: Low-frequency oscillations of the laser Doppler perfusion signal in human skin. Microvasc Res 2006, 72(3):120-127.

16. Grosse P, Cassidy MJ, Brown P: EEG-EMG, MEG-EMG and EMG-EMG frequency analysis: physiological principles and clinical applications. Clin Neurophysiol 2002, 113(10):1523-1531.

17. Bertuglia S, Colantuoni A, Arnold M, Witte H: Dynamic coherence analysis of vasomotion and flow motion in skeletal muscle microcirculation. Microvasc Res 1996, 52(3):235-244.

18. Wong FY, Silas R, Hew S, Samarasinghe T, Walker AM: Cerebral oxygenation is highly sensitive to blood pressure variability in sick preterm infants. Plos One 2012, 7(8):e43165.

19. Muller M, Bianchi O, Erulku S, Stock C, Schwerdtfeger K, Homburg Traumatic Brain Injury G: Changes in linear dynamics of cerebrovascular system after severe traumatic brain injury. Stroke 2003, 34(5):1197-1202.

20. Hsiu H, Hsu WC, Chen BH, Hsu CL: Differences in the microcirculatory effects of local skin surface contact pressure stimulation between acupoints and nonacupoints: possible relevance to acupressure. Physiol Meas 2010, 31(6):829-841.

21. Litscher G, Wang L, Huber E, Nilsson G: Changed skin blood perfusion in the fingertip following acupuncture needle introduction as evaluated by Laser Doppler Perfusion Imaging. Lasers Med Sci 2002, 17(1):19-25.

22. Hsiu H, Hsu WC, Chang SL, Hsu CL, Huang SM, Lin YYW: Microcirculatory effect of different skin contacting pressures around the blood pressure. Physiol Meas 2008, 29(12):1421-1434.

23. Litscher G: Bioengineering assessment of acupuncture, part 2: monitoring of microcirculation. Crit Rev Biomed Eng 2006, 34(4):273-294.

24. Niimi H, Yuwono HS: Asian traditional medicine: from molecular biology to organ circulation. Clin Hemorheol Microcirc 2000, 23(2-4):123-125.

25. Tsuru H, Kawakita K: Acupuncture on the Blood Flow of Various Organs Measured Simultaneously by Colored Microspheres in Rats. Evidence-Based Complementary and Alternative Medicine 2009, 6(1):77-83.

26. Hsiu H, Hsu WC, Hsu CL, Jan MY, Wang-Lin YY: Effects of acupuncture at the Hoku acupoint on the pulsatile laser Doppler signal at the heartbeat frequency. Lasers Med Sci 2009, 24(4):553-560.

27. Sandberg ML, Sandberg MK, Dahl J: Blood flow changes in the trapezius muscle and overlying skin following transcutaneous electrical nerve stimulation. Phys Ther 2007, 87(8):1047-1055.

28. Kuo TC, Chen ZS, Chen CH, Ho FM, Lin CW, Chen YJ: The physiological effect of DE QI during acupuncture. J Health Sci 2004, 50(4):336-342.

29. Kuo TC, Lin CW, Ho FM: The soreness and numbness effect of acupuncture on skin blood flow. Am J Chinese Med 2004, 32(1):117-129.
30. Holowatz LA, Thompson-Torgerson CS, Kenney WL: The human cutaneous circulation as a model of generalized microvascular function. $J$ Appl Physiol 2008, 105(1):370-372.

31. Stewart J, Kohen A, Brouder D, Rahim F, Adler S, Garrick R, Goligorsky MS: Noninvasive interrogation of microvasculature for signs of endothelial dysfunction in patients with chronic renal failure. Am J Physiol-Heart Circul Physiol 2004, 287(6):H2687-H2696

32. Rossi M, Bradbury A, Magagna A, Pesce M, Taddei S, Stefanovska A: Investigation of skin vasoreactivity and blood flow oscillations in hypertensive patients: effect of short-term antihypertensive treatment. J Hypertens 2011, 29(8):1569-1576.

33. Holowatz LA, Houghton BL, Wong BJ, Wilkins BW, Harding AW, Kenney WL, Minson CT: Nitric oxide and attenuated reflex cutaneous vasodilation in aged skin. Am J Physiol Heart Circ Physiol 2003, 284(5):H1662-H1667.

34. Tew GA, Klonizakis M, Saxton JM: Effects of ageing and fitness on skin-microvessel vasodilator function in humans. Eur J Appl Physiol 2010, 109(2):173-181

35. James MA, Tullett J, Hemsley AG, Shore AC: Effects of aging and hypertension on the microcirculation. Hypertension 2006, 47(5):968-974.

36. Gates PE, Strain WD, Shore AC: Human endothelial function and microvascular ageing. Exp Physiol 2009, 94(3):311-316.

doi:10.1186/1472-6882-13-327

Cite this article as: Wang et al:: Pilot study of blood perfusion coherence along the meridian in forearm. BMC Complementary and Alternative Medicine 2013 13:327.

\section{Submit your next manuscript to BioMed Central and take full advantage of:}

- Convenient online submission

- Thorough peer review

- No space constraints or color figure charges

- Immediate publication on acceptance

- Inclusion in PubMed, CAS, Scopus and Google Scholar

- Research which is freely available for redistribution 